\title{
A clinical study of septic abortions in a tertiary care referral centre in rural India - Still a neglected scenario which can be a preventable catastrophe
}

\author{
M.Vijayasree \\ Correspondence: Dr M.Vijayasree, Professor, Department of Obstetrics and Gynaecology, \\ Mamata General Hospital, Khammam, Andhra Pradesh, India; Email - \\ hospitalstelangana@gmail.com
}

Distributed under Creative Commons Attribution-Share Alike 4.0 International.

\begin{abstract}
Objectives: The aim of the present study was to assess the magnitude of septic abortion in a tertiary care referral hospital and study their complications. Methods: It was a retrospective study done on patients who were admitted from January 2008 to December 2012 in our hospital. Hundred thirty two (132) patients were included in the study. The demographic and clinical profile in relation to age, parity, marital status, indication of abortion, the methods of abortion used, qualification of health care provider, complications and maternal mortality were evaluated. Results: Unsafe abortion constitutes $11.6 \%$ of total abortion cases. Ninety three $(70.45 \%)$ women were in their third decade, $89 \%$ were married and $60 \%$ had abortion for birth spacing. In $30 \%$ of cases primitive methods were used, but majority of them were terminated by dilatation and evacuation method. Eighty three $(62.9 \%)$ of abortions were done by unqualified persons. Majority of women were admitted with serious complications like peritonitis (70\%), visceral injuries $(60 \%)$, hemorrhagic and septic shock, renal failure (17.4\%), and other conditions like DIC, hepatic failure and encephalopathy. Out of 73 women requiring laparotomy, 22\% were done within 24 hours of admission and $49 \%$ were performed beyond 24-48 hours. Conclusion: The present study confirms that education and accessibility of contraception, readily available, quality abortion services by trained health providers can limit morbidity and mortality arising from unsafe abortion.
\end{abstract}

Keywords: Unsafe abortion, maternal mortality, rural India.

Although abortion has been legalized in India from 1972, unsafe abortion still continues to be a major contributor of maternal morbidity and mortality. Termination of pregnancy, although a safe procedure in trained hands, can produce disastrous outcomes when performed by untrained and unauthorized people in rural settings. Nearly thirteen percent of all illegal abortions in the world are carried out in India ${ }^{1}$. Out of 20 million women who undergo unsafe abortion annually, 70,000 die while millions suffer chronic morbidities ${ }^{2}$. The aim of the study was to evaluate cases of septic abortions admitted to a tertiary care hospital over a period of five years in relation to the magnitude of unsafe abortion and also to assess various epidemiological factors like age, gravida,

Received: 4 th November 2017. Accepted: 10 th December 2017.

Vijayasree M. A clinical study of septic abortions in a tertiary care referral centre in rural India - Still a neglected scenario which can be a preventable catastrophe. The New Indian Journal of OBGYN. 2018; 4(2): 121-25. 
parity, methods of termination, outcome in terms of morbidity and mortality with a special emphasis on surgical complications.

\section{Materials and Methods}

This was a retrospective study of patients who were admitted with conditions that can be attributed to unsafe abortion such as pelvic infection, reproductive tract injury or cases of septicemia with or without visceral injury following abortion in 5 years period from January 2008 to December 2012 in our hospital which is a tertiary care centre. Being a referral hospital, the type of patients seen here are usually those with complications not manageable by health personnel at the peripheral hospitals. Hospital records of the women admitted with diagnosis of unsafe abortion were analyzed. Each case was thoroughly evaluated by detailed history, physical and biochemical examinations including liver function, renal function and coagulation profile. Detailed ultrasound examinations were performed. They were treated adequately with broad spectrum antibiotics, fluid and blood to achieve haemodynamic stability. Each case was individualized depending on the clinical profile, response to the treatment and results of the investigations and accordingly conservative and / surgical treatment was offered. Those cases requiring laparotomy, thorough exploration of abdominal and pelvic viscera was done to detect visceral injury and presence of pus in peritoneal cavity. Depending on the severity, uterine injuries were dealt with either by repair or hysterectomy and bowel injuries were handled with either by resection and anastomosis, colostomy or ileostomy was done in few cases where it was indicated. Data are analyzed in number and percentage.

\section{Results}

A total of one hundred and fifty seven subjects were admitted with the diagnosis of unsafe abortion in the 5 year period, out of total 1133 abortion cases, so septic abortion contributes to $11.6 \%$ of total abortion cases and out of these - complete records of $132(84 \%)$ women were available for analysis. All the statistical analysis was done taking into consideration only these 132 subjects.

In our study, the majority of women $(70.45 \%, \mathrm{~N}=93)$ were in the third decade of their lives and only $6(4.5 \%)$ women were in their teens. Nine percent women (13) were unmarried whereas large majority $(89 \%, \mathrm{~N}=117)$
Table 1: Characteristics of patients of unsafe abortions $(\mathbf{N}=132)$

\begin{tabular}{lll}
\hline Categories & & Number (\%) \\
\hline Age in years & $14-19$ & $6(4.5 \%)$ \\
& $20-30$ & $93(70.45 \%)$ \\
& $>30$ & $33(25 \%)$ \\
Marital status & Married & $117(88.63 \%)$ \\
& Unmarried & $13(9.83 \%)$ \\
& Widow / separated & $2(1.54 \%)$ \\
Parity & 0 & $12(9.09 \%)$ \\
& 1 & $28(21.21 \%)$ \\
Gestational & 5-12 & $92(69.69 \%)$ \\
age in weeks & $13-20$ & $74(56 \%)$ \\
& $>20$ & $43(32.6 \%)$ \\
& Not known & $5(3.8 \%)$ \\
& & $10(7.6 \%)$ \\
\hline
\end{tabular}

were married and living with their spouses. Although majority $(56 \%, \mathrm{~N}=74)$ underwent abortion in the first trimester, more than one third of women had it beyond 12 weeks of gestation. Out of them, 5 women had illegally

Table 2: Causes for seeking abortion

\begin{tabular}{ll}
\hline Causes & Number (\%) \\
\hline Unmarried & $13(9.8 \%)$ \\
Widow & $2(1.5 \%)$ \\
Birth spacing & $79(59.8 \%)$ \\
Female foetus & $9(6.8 \%)$ \\
Incomplete / missed abortion & $29(22 \%)$ \\
\hline
\end{tabular}

induced abortion beyond 20 weeks (Table 1). When enquired about the reason for abortion 79 (60\%) used abortion as a method of birth spacing or limiting family size. Nine $(6 \%)$ women opted for abortion to get rid of a female fetus (Table 2).

Table 3: Methods employed to induce abortion and health care provider ( $\mathrm{N}=132$ )

\begin{tabular}{|c|c|c|}
\hline \multicolumn{2}{|l|}{ Methods } & Number (\%) \\
\hline \multicolumn{2}{|l|}{ Dilatation and Evacuation } & $67(50.75 \%)$ \\
\hline \multicolumn{2}{|l|}{ Primitive methods } & $37(28.03 \%)$ \\
\hline \multicolumn{2}{|c|}{ Injections and vaginal pessaries } & $28(21.21 \%)$ \\
\hline Health care provider & No $(\%)$ & Mortality \\
\hline Qualified Doctor & $37(28 \%)$ & $6(16.2 \%)$ \\
\hline Unqualified & $83(62.9 \%)$ & $21(25.3 \%)$ \\
\hline a) Nurse (ANM) & 26 & \\
\hline b) Traditional & 57 & \\
\hline Not revealed & $12(9.09 \%)$ & $2(16.6 \%)$ \\
\hline
\end{tabular}


Table 4: Complications and Mortality in Septic Abortion

\begin{tabular}{lll}
\hline Complication & $\begin{array}{l}\text { No. of cases } \\
(\%)\end{array}$ & $\begin{array}{l}\text { Maternal } \\
\text { deaths }\end{array}$ \\
\hline Peritonitis & $92(69.69 \%)$ & 8 \\
Septicemia & $49(37.12 \%)$ & 7 \\
Injuries & $79(59.8 \%)$ & 2 \\
Uterine perforation & $49(75.38 \%)$ & \\
Uterine perforation & with & $24(18.18 \%)$ \\
bowel injury & 02 & \\
Bladder injury & 04 & \\
Vaginal injury & $28(21.2 \%)$ & \\
Shock & $23(17.42 \%)$ & 5 \\
Acute renal failure & 2 & 2 \\
Encephalopathy & 2 & 1 \\
Jaundice & 3 & 2 \\
DIC & & \\
\hline
\end{tabular}

About one third of the procedures (37) were carried out by primitive methods like using sticks, roots, vaginal paste, insertion of catheters and herbal medicines. However, more than half of the procedures were done by conventional dilatation and evacuation or suction and evacuation (Table 3 ).

Infection was the common event in all the patients included in the study. While in one third of the subjects

Table 5: Types of Intervention Needed

\begin{tabular}{ll}
\hline Interventions & No $(\%) \quad(\mathbf{N}=132)$ \\
\hline Conservative & $12(9.09 \%)$ \\
Dilatation \& Evacuation & $46(34.84 \%)$ \\
Laparotomy & $73(55.30 \%)$ \\
Posterior colpotomy & 1 \\
\hline
\end{tabular}

the infection was localized to the genital tract, majority $(70 \%, \mathrm{~N}=92)$ developed generalized peritonitis. Visceral injury were detected in $79(60 \%)$ cases, of which uterine injury was the commonest (55\%, N=73), followed by bowel injury (18\%, N=24). One in every 5 women (28) was admitted in a state of shock, of these majority were septic shock and the remainder were in shock due to severe blood loss. One fourth of the women subsequently developed multiple organ dysfunctions in the form of renal failure (17.42\%), encephalopathy, hepatic failure, DIC (Table 4). More than half of the cases (73) needed laparotomy, while dilatation and evacuation and conservative treatment were all that was needed for the rest of the cases (Table 5). Among those requiring surgery, 49\% laparotomy was performed beyond 24-48 hours of admission, while in $22 \%$ of cases it was done promptly within 24 hours of admission. Various surgeries done as treatment option were depicted in the Table 6 .

Table 6: Surgical procedures needed at the time of Laparotomy $(\mathbf{N}=73)$

\begin{tabular}{|c|c|}
\hline Procedures & No $(\%)$ \\
\hline $\begin{array}{l}\text { Repair of uterine perforation with } \\
\text { peritoneal lavage and drainage }\end{array}$ & $27(37 \%)$ \\
\hline Only peritoneal lavage \& drainage & $13(17.80 \%)$ \\
\hline Repair of Uterine perforation and primary & \\
\hline bowel Repair & $12(16.4 \%)$ \\
\hline Intestinal resection \& anastomosis & $5(6.84 \%)$ \\
\hline Colostomy \& Ileostomy & $7(9.88 \%)$ \\
\hline $\begin{array}{l}\text { Subtotal hysterectomy with peritoneal } \\
\text { lavage }\end{array}$ & $7(12.32 \%)$ \\
\hline Subtotal hysterectomy with bladder repair & 2 \\
\hline
\end{tabular}

Repair of uterine perforation and peritoneal lavage were the commonest procedures done. In the present study 29 out of the 132 women with septic abortion expired making a case fatality rate of $21.96 \%$. During the study period 231 Women died due to pregnancy related causes in our hospital. Thus unsafe abortion constitutes $12.5 \%$ of total maternal mortality in our institution. Of the abortions carried out by doctors $16.2 \%$ (6 out of 29) women expired, while $25.3 \%$ (21 out of 29) of those performed by unqualified persons proved fatal. Out of 73 women who required surgical treatment, 7 expired and there was no maternal mortality when surgery was performed within $24 \mathrm{hrs}$ of admission.

\section{Discussion}

The burden of unsafe abortion in our institute constitute $11.6 \%(\mathrm{~N}=157$ out of 1133$)$ of total abortion cases who were admitted. Incidence of septic abortion remains similar (9-26.5\%) in other studies ${ }^{3,4}$. As in other studies, ${ }^{3,5}$ our study also shows that three fourth of the women who underwent unsafe abortion were between 20 - 30 years of age. In countries where contraception is widely available, more than $50 \%$ of abortions were for women less than 25 years of age, whereas in countries with no tradition of contraceptive use and limited availability of contraception, such as those in central and Eastern Europe, majority of the terminations were 
performed in women aged 35 years or more. Thus our results are likely to be due to suboptimal use of contraceptives ${ }^{6}$. Although in developed nations the abortion ratio is higher among unmarried women ${ }^{7}$, in our study, more than $90 \%$ women were married which is consistent with other studies ${ }^{3-5,8}$. It appears that for majority of women who underwent unsafe abortion, it was probably the only available method of family planning. Either these women were unaware of the methods of contraception or were not readily available to them. Majority $(58.3 \%)$ of our women sought abortion in the first trimester which is similar to other studies ${ }^{5,9}$.The advanced gestation at the time of abortion in nearly one third of the women in the present study could be due to lack of easily accessible medical services and may also be related to the complexity of MTP act where it requires approval of two doctors when pregnancy beyond 12 weeks needs termination. Although nearly one third of the health care providers were medical doctors, great majority (62\%) were unqualified, where as in the experience of other authors $57-77 \%$ abortions were carried out by untrained and unqualified people ${ }^{5,8,9}$.

As per MTP act only doctors who underwent training in MTP are allowed to provide abortion services. Twenty eight percent of unsafe abortions were carried out by doctors out of which 6 women expired in our study, which was consistent with the results of others ${ }^{5,10-12}$ where medically qualified persons were responsible for considerable number of unsafe abortions. It therefore cannot be assumed that the doctors always know how to perform safe abortion. Not only in India, are many doctors in developed nations not properly trained to render safe abortion services. Complication rates are significantly higher when general physicians without formal training perform abortion. Examination of rates of complication occurring in a teaching hospital based abortion clinic show the rates are significantly lower for resident physicians after training compared to before training ${ }^{13}$. Thus availability of huge number of adequately trained personnel remains the key to reduce unsafe abortions.

Uterine perforation was the commonest visceral injury $(\mathrm{N}=73,55 \%)$ in the present study. The wall of the pregnant uterus is soft and relatively thin and very vulnerable to perforation during surgical abortion particularly done by primitive methods. Frequency of uterine perforation varies from 0 per 1000 procedures to 4 per 1000 procedures ${ }^{14}$. The high incidence of uterine injury in our study was due to primitive techniques adopted by large number of unqualified people. The frequency of bowel injury has varied between 5 to $18 \%$ of the cases ${ }^{5,9,15}$ in different studies and in our study 24 women had various kinds of bowel injuries. In our study 55\% women required laparotomy and our results were comparable with others where the rates of laparotomy varied from $16-52 \%{ }^{5,15}$. As the patients were referred late to the tertiary care center with high grades of sepsis, majority needed laparotomy. Therefore early referral and safe abortion services by skilled personnel in peripheral centers are necessary to limit morbidity and mortality due to unsafe abortions.

Unsafe abortion killed 29 lives in our study making abortion mortality ratio $25.6 / 1000$ abortions. And case fatality rate was $21.96 \%$ compared to 0.6 in Africa, 0.4 in Asia and 0.1 in Latin America. Maternal deaths attributed to abortion were found to be $9 \%$ to $26.4 \%$ in various studies $5,8,9,16,17$. The high mortality rate in the current study was due to the fact that the complications that resulted from unsafe abortion required tertiary level care. There was much delay in referring the patients to tertiary centers and the delay may be linked to the delay in the diagnosis of complications by unqualified persons and also to some extent social reasons. In our study where early surgical exploration within 24 hours of admission was undertaken there was no maternal death and hospital stay was reduced to less than one week, compared to high maternal mortality (7 out of $73,68.5 \%$ ) and increased hospital stay $(47.6 \%$, more than two weeks ) when surgery was done beyond 24 hours after admission. Meqafu et al ${ }^{18}$ in their study also stressed the need of early aggressive surgical management to reduce the maternal mortality, $16.4 \%$ of their 67 patients of septic abortion had intestinal injuries. None of the women died when early colostomy was performed, whereas when simple closure of perforation or intestinal resection and anastomosis was done the mortality was $66.6 \%$.

\section{Conclusion}

The present study confirms that unsafe abortion is one of the great neglected healthcare problems in India and more so in rural India where lack of education and adequate trained health care providers and freely available 
quality abortion services led to very high maternal morbidity and mortality. This study shows that married and multiparous women in the third decade of their lives are the principal sufferers of unsafe abortion and abortion is being used as an alternative to contraception.

A high degree of commitment from all categories of health professionals for prevention of unsafe abortion is needed. All including the male members of the family need to be educated regarding the contraception and safe abortion because the causes of unsafe abortion are rooted in a complex set of socio-demographic circumstances. It can be emphasized that only legalization of abortion is not sufficient to reduce the number of unsafe abortions. The fact that $60 \%$ women approach unskilled health care provider, in spite of abortion being legalized. This emphasizes the need to make abortion service freely available and easily accessible in the society. Also MBBS doctors need to be properly trained to provide quality abortion services. Early diagnosis of complications and prompt referral to tertiary care centers also will save many lives and limit morbidities.

\section{Conflict of interest: None. Disclaimer: Nil.}

\section{References}

1.Dixon-Mueller R. Abortion policy and women's health in developing countries. Int J Health serv. 1990; 20(2): 297314.

2.World Health Organisation. Abortion: A tabulation of Available Data on the frequency and Mortality of Unsafe abortion, 2nd edn. Geneva: WHO; 1994.

3.Meenakshi, Sirohiwal D, Sharma D. A review of septic abortion. J Obstet Gynecol Ind. 1995; 45(2):186-90

4.Guin G, Gupta A, Khare S, Chandra M, Kalkar S. A study of septic abortions: trends in a tertiary hospital. J Obstet Gynecol Ind. 2005; 55(3): 257- 60.

5.Jain V, Saha SC, Bagga R, Gopalan S. Unsafe abortion: A neglected tragedy. Review from a tertiary care hospital in India. J Obstet. Gynaecol. 2004; 30(3): 197-201.

6.World Health Organisation. Medical methods for termination of pregnancy. Report of a WHO Scientific group. World Health Organ Tech Rep series 1997; 871: I VII. pp. 1-110.
7.Office of Population Censuses and Surveys. British Statistics. London: The Stationary Office, 1994.

8.Sood M, Juneja Y, Goyal U. Maternal mortality and morbidity associated with clandestine abortions. Journal of the Indian Medical Association. 1995; 93(2): 77 - 9.

9.Naib JM, Siddiqui MI, Afridi B. A review of septic induced abortion cases in one year at Khyber teaching hospital, Peshwar. J Ayub Med Coll Abbottabad. 2004; 16(3): 59-62.

10.Konze JC, ObisesanKA, Ladipo A. Health and economic consequences of septic induced abortion. Int J Gynaecol Obstet. 1992; 37:193-7.

11.Agrawal A, Salhan S. Septic abortion - Current scenario in a tertiary care hospital. J Obstet Gynecol Ind. 2008; 58(2): 147-51.

12.Sule-odu AO, Olatunji AO, Akindele RA. Complicated induced abortion in Sagamu, Nigeria. J Obstet Gynaecol. 2002; 22: 58-61

13.Darney PD. Training physicians in elective abortion techniques in United States. In Landy U, Ratnam SS (eds). Prevention and treatment of contraceptive failure. New York: Plenum Press; 1986. pp 133-40

14.Fried G, Ostlun E, Ullberg C, Bygdeman M. Somatic Complications and contraceptive techniques following legal abortion. Acta Obstet gynecol Scand. 1989; 68(6): 515-21.

15.Rana A, Pradhan N, Gurung G, Singh M. Induced septic abortion: A major factor in maternal mortality and morbidity. Journal of Obstetrics and Gynaecology Research. 2004; 30(1): 3-8.

16.Lapido OA. Preventing and managing complications of induced abortions in third world countries. Int J Gynecol Obstet. 1989; 30: 21-8

17.Fawole AA, Aboveii AP. Complications from Unsafe abortion: Presentations at Iorin, Nigeria. Niger J Med. 2002:11(2):77-80.

18.Meqafu U. Bowel injury at septic abortion: The need for more aggressive management. Int J Gynecol Obstet. 1980; 17(5): 450-3.

\section{Vijayasree ${ }^{1}$}

${ }^{1}$ Professor, Department of Obstetrics and Gynaecology, Mamata General Hospital, Khammam, Andhra Pradesh, India. 